\title{
LEISHMANLASIS PRESENTING AS SEVERE ANAEMIA IN AN ADULT FEMALE NIGERIAN
}

1Kazeem, O. D., 1Oyekunle, A. A., 1Salawu, L., 1Adediran, I. A., 1Akinola, N. O., 2Badmos, K..B., 20jo, O. S., 1 Durosinmi, M. A.

Departments of ${ }^{1}$ Haematology/Blood Transfusion, and 2Morbid Anatomy Obafemi Awolowo University Teaching Hospitals Complex, Me-Ife, Nigeria

\author{
Correspondence to: $\quad$ L. Salawn \\ Department of Haematology and Immunology \\ OAU, Me-Ife, Nigeria \\ (E-mail: 1salawu2002@yahoo.co.uk, 1salawrugoauife.edu.ng)
}

Visceral leishmaniasis is a rare cause of anaemia. We report a case of visceral leishmaniasis presenting an severe anaemia and pyrexia of unknown origin in an adult female Iigerian. The objective was to highlight the importance of exhauntive investigations in the diagnosis of anaemia and pyrexia of unknown origin in our environment.

Reywords: vieceral leishmanlasis; chronic anaemia; pyrexia of unknown origin; Nigeria.

\section{INTRODUCTION}

Leishmaniasis is a zoonotic infection caused by the protozoa belonging to the genus Leishmania. It is an intracellular parasite that infects the reticulo-endothelial system (RES) and which is manifested by gradual onset, spectrum of disease such as localized ulcers or wildly disseminated progressive lesion of the skin, mucus membrane or the entire RES (1). The reservoir of infection in African leishmaniasis includes the rodents and domestic animals such as dogs; and is transmitted to man through the bite of sandflies (Phlebotomus and Lutzomyia species).

Although leishmaniasis is not a common disease in Nigeria, exhaustive investigations in the diagnosis of anaemia and pyrexia of unknown origin in our environment may be rewarding as in this case report.

\section{Case Report}

Miss A. A, a 20-year-old nursing student, presented with a three weeks history of fever, progressive body weakness and headache. Fever was high grade, intermittent and associated with chills and rigors. Four days before presenting in the hospital, she developed abdominal pain that was associated with vomiting and passage of non-bloody, nonmucoid watery stool. She also gave a history of watery, non-mucoid and non-foul smelling vaginal discharge; but denied any previous sexual exposure. She used several anti-malaria drugs without any sustained remission in fever.

Physical examination revealed an acutely ill-looking, febrile, and markedly pale but anicteric young lady. There was no significant peripheral lymphadenopathy or oedema. There was tenderness in the right iliac fossa but rebound tenderness was not elicited. Spleen was enlarged $6 \mathrm{~cm}$ below the left costal margin; there was no hepatomegaly.

Serial full blood count showed haematocrit of between 12 and $26 \%$ (median = $22 \%$, platelet count slightly reduced at a range of $55-131 \times 109 / \mathrm{L}\left(\right.$ median $\left.=79 \times 10^{9} / \mathrm{L}\right)$ and essentially normal white cell count (with differentials) of $1.9-4.3 \times 10^{9} / \mathrm{L}$ (median $=3.1$ $x \quad 10 \% / \mathrm{L}$. The reticulocyte counts were consistently < $1 \%$. Bone marrow aspiration 
showed erythroid hyperplasia and negative iron store. Serum biochemical parameters showed hypoproteinaemia of $59 \mathrm{~g} / \mathrm{L}$ with reversal of albumin/globulin ratio.

Repeated septic work-up yielded no growth and stool was free of ova and parasites. Screening for human immunodeficiency. virus (HIV), hepatitis $\mathrm{C}$ virus (HCV) and hepatitis B surface antigen (HBsAg) were negative. Abdominal ultra-sonography did not reveal any pathology either intra-abdominally or in the enlarged spleen.

Fever remained high despite antimalarial, antibiotics, anti-fungal and anti-viral agents. She had 7 units of packed red cells while on admission. The spleen increased in size to $14 \mathrm{~cm}$ during admission and the liver also became palpable at $7 \mathrm{~cm}$. Liver biopsy undertaken a month into admission confirmed the presence of Leishmania-Donovan (LD) bodies in the Kupffer cells (Fig 1). A diagnosis of leishmaniasis was made.

Fig1: Liver histology (x640) showing enlarged Kupfier cell DISCUSEION

Reports on leishmaniasis in Nigerians are very scanty. The few reported cases presented with cutaneous lesions $(2,3)$, and only one case presented with visceral type (4) as seen in this patient. In a review of dermatological lesions seen over a period of nine years in a tertiary hospital in Nigeria, leishmaniasis accounts for about $0.1 \%$ of all mass (2. Similarly, in stological

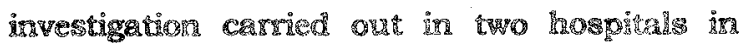

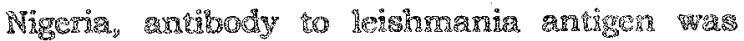

detected in only $9.5 \%$ of cases compared to $100 \%$ in malaria (5).

Anaemia featured prominently in this case, as she was blood transfusion dependent. The patient had a total of 7 units of packed red cells during her 24 weeks of hospitalization. Factors such as splenic sequestration $(6,7,8)$, ineffective erythropoiesis (7), hypersplenism and haemodilution (6); and immune-mediated red blood cell destruction $(9,10)$ have been linked with the pathogenesis of anaemia in visceral leishmaniasis. This patient presented with massive splenomegaly and hepatomegaly, both of which may sequester and/or destroy significant red cells. The persistent reticulocytopaenia of $<1 \%$, depleted iron store and hypoproteinaemia also suggest hypoproliferative anaemia in this patient. The presence of all these factors in this patient suggests that the mechanism of anaemia in visceral leishmaniasis could be multi-factorial.

The recurrent high fever seen in this patient could not be attributable to neutropaenia as reported in other cases (7), as the patient had normal white cell count including the differentials. However the $T$ cell response depression and the disturbances in cytokine networks associated with viscera leishmaniasis (11) could cause several opportunistic infections that may be responsible for the recurrent episodes of fever recorded in the patient.

\section{REFEROTCES}

\begin{tabular}{|c|c|}
\hline 1. & 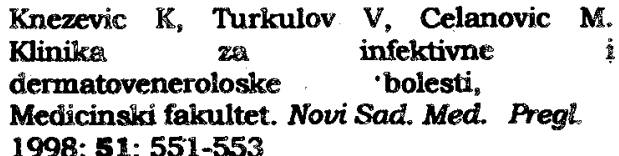 \\
\hline 2 & $\begin{array}{l}\text { Obasi OE. Cutaneous leishmaniasis in } \\
\text { Nigeria. Im. J. DermatoL 1991; 30:274- } \\
275\end{array}$ \\
\hline & 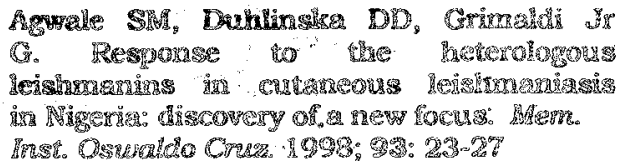 \\
\hline
\end{tabular}


4. Salami AK, Oluboyo PO, Onile BA, Odedina EA. Kala azar in a Nigerian. Report of a case with a fatal outcome. Afr. J. Clin. Exper. Microbiol. 2004; 5(1): 40-45

5. Sixl W, Schneeweiss WD, Withalm $H$, Schuhmann G, Rosegger H. Serological testing of human blood samples for infectious diseases in the Abeokuta and the Minna Hospitals, Nigeria. J. Hyg Epidemiol. Microbiol. Immunol. 1987; 31: 490-491

6. Pippard MJ, Moir D, Weatherall DJ, Lenicker HM. Mechanism of anaemia in resistant visceral leishmaniasis. Ann. Trop. Med. Parasitol. 1986; 43: 317-323

7. Marwaha N, Sarode R, Gupta RK Garewal G, Dash S. Clinicohaematological characteristics in patients with Kala-azar. A study from northwest India. Trop Geogr. Med. 1991; 43: 357-362
8. al-Jurayyan NA, al-Nasser MN, al-Fawaz IM, et al. The haematological manifestations of visceral leishmaniasis in infancy and childhood. $J$. Trop. Paediatr. 1995; 41: 143-148

9. Pontes De Carvalho LC, Badaro R, Carvalho EM, et al. Nature and incidence of erythrocyte-bound IgG and some aspects of physiopathogenesis of anaemia in American visceral leishmaniasis.

Clin.

Exper. Immunol. 1986; 64: 495-502

10. Pollack S, Nagler A, Liberman D, Oren I, Alroy G, Katz R, Schehter Y. Immunological studies of pancytopaenia in visceral leishmaniasis. $1988 ; 24: 70-74$

11. Ali A. Leishmaniasis and HIV/AIDS coinfections: review of common features and management experiences. Ethiop. Med. $J$. 2002; 40: 37-49 